\title{
Use of Psychology and Behavioral Economics to Promote Healthy Eating
}

\section{Citation}

Roberto, Christina A., and Ichiro Kawachi. 2014. "Use of Psychology and Behavioral Economics to Promote Healthy Eating." American Journal of Preventive Medicine 47 (6): 832-37. https:// doi.org/10.1016/j.amepre.2014.08.002.

\section{Permanent link}

http://nrs.harvard.edu/urn-3:HUL.InstRepos:41275484

\section{Terms of Use}

This article was downloaded from Harvard University's DASH repository, WARNING: This file should NOT have been available for downloading from Harvard University's DASH repository.

\section{Share Your Story}

The Harvard community has made this article openly available.

Please share how this access benefits you. Submit a story.

\section{Accessibility}




\title{
Use of Psychology and Behavioral Economics to Promote Healthy Eating
}

\author{
Christina A. Roberto, PhD, Ichiro Kawachi, MD, PhD
}

\begin{abstract}
Understanding the psychology of how people make decisions can shed light on important factors contributing to the cause and maintenance of public health problems like obesity. This knowledge can and should inform the design of government and private-sector public health interventions. Several insights from psychology and behavioral economics that help explain why people are particularly vulnerable to the current food environment are discussed. These insights fall into the following categories: the influence of starting points (status quo bias and anchoring effects); communicating health information (simplicity and framing); and unintended consequences of policy interventions (compensation, substitution, and the peanuts effect). The paper discusses opportunities for improving the design of food policies and interventions by altering default options, providing the public with simple and meaningful nutrition information, carefully constructing the framing of public health messages, and designing food policies to minimize unintended consequences, such as compensation and substitution.
\end{abstract}

(Am J Prev Med 2014;47(6):832-837) @ 2014 American Journal of Preventive Medicine

\section{Introduction}

$\mathrm{S}$ ocial scientists have been studying decision making for decades, but public health interventions have been slow to incorporate these insights. In their book Nudge, Thaler and Sunstein ${ }^{1}$ popularized the idea that insights into how people make decisions can be leveraged to encourage wiser choices without abridging freedom to choose. This philosophy of "libertarian paternalism" encourages private institutions and governments to construct choice environments that "nudge" people toward decisions that are in their long-term selfinterest. The appeal of nudge strategies is that they preserve freedom, although some worry that pursuing nudges will discourage implementation of restrictive, but more effective policies. We argue that behavioral nudges should not replace strategies known to be effective (such as taxing "bads" like cigarettes), but should be harnessed to make policies and interventions more effective.

In a recent review, Thorgeirsson and Kawachi ${ }^{2}$ discuss the application of behavioral economics to a broad range of public health problems. The current paper builds on this broad overview by focusing in depth on poor diet

From the Departments of Social and Behavioral Sciences (Roberto, Kawachi) and Nutrition (Roberto), School of Public Health, Harvard University, Boston, Massachusetts

Address correspondence to: Christina A. Roberto, PhD, Department of Social and Behavioral Sciences, Harvard School of Public Health, Room 617, 677 Huntington Avenue, Boston MA 02115. E-mail: croberto@hsph. harvard.edu.

$0749-3797 / \$ 36.00$

http://dx.doi.org/10.1016/j.amepre.2014.08.002 and obesity. ${ }^{3}$ Specifically, it examines how the behavioral sciences can aid understanding of why people have difficulty eating healthfully and how to leverage that knowledge to design better interventions and policies to address obesity.

\section{Why Is It Hard to Eat Healthfully?}

In the current food environment, nutrient-poor, caloriedense foods are widely available, inexpensive, heavily marketed, not clearly labeled, and served in large portions. ${ }^{4-6}$ This environment makes it easy to choose unhealthy foods, even when those choices are inconsistent with long-term preferences. ${ }^{7,8}$ People are also susceptible to present-biased preference, the tendency to place disproportionate weight on momentary gratification relative to future costs and benefits. ${ }^{9-11}$ When unhealthy, tasty food is available, it is easy to be influenced by the immediate enjoyment of the food, rather than delayed health costs associated with eating it. To make matters worse, people are vulnerable to the planning fallacy, the tendency to be overly optimistic about one's ability to carry out future intentions. ${ }^{12}$ This can lead to false predictions that one will alter entrenched eating habits or start exercising "tomorrow."

\section{The Influence of Starting Points: Status Quo Bias and Anchoring Effects}

Much of one's daily eating habits are "mindless,"habitual, automatic, and guided by default options. ${ }^{13}$ 
People have a strong tendency to stick with default options, a phenomenon known as the "status quo bias." Unfortunately, the vast majority of food defaults encourage unhealthy choices. Restaurant defaults include large portion sizes and unhealthy side dishes (e.g., french fries), so those who want healthier options must request a substitute-something the status quo bias discourages. Such defaults are also influential because they shape norms; large portion sizes convey that it is not unreasonable to eat the entire portion in one sitting.

Unhealthy defaults can also interact in problematic ways with anchoring effects. Anchoring refers to the tendency to base decisions on initial information provided. For example, people's estimates of unknown quantities are lower when first considering a small rather than large quantity. ${ }^{15}$ This tendency may explain why people eat more when served larger portions. In one study, participants used 30\% more pasta when they were given a 2-pound box compared to a 1-pound box, and $23 \%$ more oil from a 32 -ounce bottle than a 16 -ounce bottle when making fried chicken. ${ }^{16}$ This indicates that people base their usage volume on the package size. However, much of the portion size research has only examined unhealthy foods; therefore, more studies are needed to determine whether portion size effects are as strong with healthy foods.

\section{Communicating Health Information: Simplicity and Framing}

The importance of simplicity in health communication is critical, but often overlooked. Psychologists have described two systems of thought: "System 1," which is fast and relatively effortless, and "System 2," which is slower and effortful. ${ }^{17}$ Although quick System 1 thinking drives many eating decisions, many efforts to communicate nutrition information to the public rely on numeric data, which requires System 2 thinking. Research shows that people have difficulty processing numeric information, ${ }^{18,19}$ making the use of numbers in health communication problematic. For example, the Nutrition Facts Panel presents nutrient information in grams and milligrams accompanied by percentages. Serving sizes appear in cups, ounces, or grams. Many weight-loss programs require patients to count calories, and doctors talk to patients about maintaining a healthy BMI (calculated by weight divided by height squared).

Peters and colleagues ${ }^{20,21}$ offer several reasons why numbers present a processing challenge: they are abstract, the meaning of the same number changes in different contexts, and differences in numbers typically reflect small and unfamiliar discrepancies. Other research $^{22}$ has found that depicting statistical information in pictographs reduced medical patients' reliance on anecdotes when making decisions, and another study ${ }^{23}$ found that evaluative labels (e.g, "normal," "positive") presented with prenatal screening test results were better able to influence risk perceptions and behavioral intentions than were numbers.

Such research can inform current debates about the type of nutrition labels that should be displayed on the front of packaged foods. The food industry recently released a front-of-package labeling system called Facts Up Front, ${ }^{24}$ which displays grams and milligrams for saturated fat, sugar, and sodium alongside daily value percentages. The industry can also list up to two positive nutrients on the label (e.g., fiber, vitamins). In addition to having lots of information, the label is small and appears in only one or two colors. This is in contrast to traffic light labels used by some food manufacturers in the United Kingdom and recently adopted, although not yet implemented, by Ecuador. The label uses evaluative red, yellow, and green circles to alert customers to low, medium, or high levels of nutrients, respectively. The benefit of a traffic light approach is that it caters to System 1 thinking by leveraging automatic associations between "red" and "stop" and "green" and "go." ${ }^{25}$ The comprehension of traffic light labels, especially among those of lower SES, further increases by including "low," "med," and "high" text. ${ }^{26}$ Given research suggesting that individuals of lower SES suffer from a "bandwidth tax," 27 simplistic communication of information that relies on System 1 processing might help reduce disparities in health interventions. One study found that traffic light labels and a choice architecture intervention in a hospital cafeteria significantly increased the purchase of "greenlight" items and decreased the purchase of "red-light" ones, ${ }^{28}$ suggesting it may be a more effective labeling system than more numeric-based approaches like Facts Up Front.

By making certain aspects of a message salient, ${ }^{29}$ the framing of public health messages can influence beliefs and behaviors. ${ }^{30}$ For example, the phrasing of First Lady Michelle Obama's childhood obesity campaign "Let's Move!" promotes exercise, not diet; the campaign is not titled, "Let's Eat Less." One concern is that the exercise framing could have a negative impact on food-related beliefs and behaviors. In one study, ${ }^{31}$ people who attributed obesity to a lack of exercise (as opposed to excessive caloric intake) were more likely to be overweight, and the belief that exercise contributes more to weight gain than diet led to greater food consumption in the lab. These findings suggest a need to evaluate the influence of such messaging.

Marketers also make certain aspects of products salient to create "health halos" that influence consumer 
perceptions. ${ }^{32}$ Many candies display labels that read "this is a fat-free food," which is factually truthful, but may influence consumers to think the overall product is healthier than is true. Similarly, a "Smart Choices" front-of-package nutrition label on an unhealthy cereal was found to boost overall perceptions of the cereal's healthfulness. ${ }^{33}$ Additionally, red meats are framed as " $85 \%$ lean" rather than " $15 \%$ fat," likely to increase perceptions of healthfulness. By contrast, labeling healthy foods as "healthy" can lower demand for the product, possibly because consumers equate "healthy" with "tastes bad." 34

\section{Unintended Consequences: Compensation, Substitution, and the Peanuts Effect}

The behavioral sciences can help shed light on why some well-intentioned interventions backfire and how to design interventions to minimize unintended consequences. One challenge to altering behavior is the tendency to compensate for behavioral changes. For example, people who switch to "low-nicotine" cigarettes may compensate by smoking more cigarettes or inhaling more deeply. ${ }^{35} \mathrm{In}$ a Danish RCT, ${ }^{36}$ compensatory behavior (in the form of physical inactivity) was observed following vigorous exercise. Healthy but sedentary and moderately overweight men were assigned to three groups: no exercise; a moderate-exercise regimen (300 kcal/day); or a highexercise regimen $(600 \mathrm{kcal} /$ day $)$. The men were instructed not to change their diets, and to keep detailed daily food diaries. After 13 weeks, the exercise-induced energy expenditure in the more intensive exercise group was twice that of the moderate exercise group; however, the resulting accumulated energy balance, calculated from changes in body composition, was not statistically different between the groups. Thus, the intensive-exercise regimen was ineffective, presumably due to compensatory behavior. The researchers speculated that the men in the high-exercise regimen were more tired later in the day, engaging in less physical activity after exercising (e.g., taking the elevator instead of stairs). ${ }^{36}$

In the food realm, one study ${ }^{37}$ found that people ate more M\&M candies when they were labeled as low fat. People may also compensate for exercise by eating more calories after the workout than they burned during it. ${ }^{38}$ Unfortunately, people do not tend to compensate in a healthier direction. Study participants given larger snack bags of potato chips ate more chips, but they did not compensate by eating less at a dinner meal later that night. $^{39}$

Unintended consequences can also arise from substitution behavior. For example, cigarette taxes depressed sales, but sales of other tobacco products (e.g., cigars) increased. ${ }^{40}$ People reduced their fat consumption following government recommendations to do so, but instead of decreasing their caloric intake, they substituted carbohydrates for fat, leading to an even greater increase in caloric intake. ${ }^{41}$ Experts have advocated for a tax on sugar-sweetened beverages to curb consumption of "empty" calories, but it will be important to evaluate (and anticipate) the demand for substitutes for sugarsweetened beverages unaffected by the tax (e.g., energy drinks versus diet drinks) and design policies with this in mind.

The peanuts effect presents a further challenge to eating healthfully. This is the tendency to discount very small individual losses and fail to consider the cumulative effect of multiple losses. ${ }^{42}$ For example, smaller snacksized portions of popular foods have been introduced by many manufacturers (e.g., 100-calorie packs of Oreo cookies), but one study ${ }^{43}$ found that such preportioned packs work well for those not consciously trying to diet or restrain their eating. However, for restrained eaters (who are most likely to purchase these products), the offering of this small temptation ("mere peanuts") led to greater overall consumption. ${ }^{43}$ A related phenomenon has been called the "what the hell" effect. For example, a restrained eater who consumes a single cookie might decide that because she has already broken her diet she may as well keep eating. ${ }^{44}$

\section{Using Behavioral Science to Promote Healthy Eating}

The first part of the paper used behavioral science insights to explain why it is difficult to eat healthfully in the current food environment. This section uses behavioral science insights to inform three policies: the presentation of dietary guidelines, menu labeling, and a portion cap policy on sugar-sweetened beverage containers.

\section{Pictorial Food-Based Dietary Guidelines and Simplicity}

The 2005 Food Guide Pyramid (MyPyramid) was widely criticized for being overly complex. ${ }^{45}$ The updated version of the Pyramid graphic used rainbow stripes of varying proportions to convey serving amounts across food categories. Individuals could obtain personalized guidelines for a balanced diet from MyPyramid's website. A sample guideline might provide daily consumption recommendations, such as 9 ounces of grains, 3.5 cups of vegetables, 2 cups of fruits, 3 cups of milk, and 6.5 ounces of meat and beans. The messaging is complex, requiring understanding and recall of large amounts of information 
and visualization of varying serving amounts, for example, what does a 6.5-ounce serving of steak look like?

Riis and Ratner ${ }^{46}$ compared the MyPyramid graphic to a simpler "half-plate" graphic: an image of a plate, half of which was colored green and accompanied by the message "be sure to fill half of your plate at every meal with fruits and vegetables." When asked to recall the message immediately following exposure to the graphic, $85 \%$ recalled the half-plate message, whereas only $19 \%$ recalled the MyPyramid guidelines. The half-plate graphic was also judged to be more motivating. Further, among nutrition-conscious consumers, those who saw the half plate chose more fruits and vegetables when assembling a dinner meal 1 month later. Moreover, 1 month after exposure, $62 \%$ of respondents recalled the half-plate message, whereas only $0.7 \%$ recalled the MyPyramid guidelines. ${ }^{46}$ This suggests it might be better to sacrifice the precision of dietary recommendations to provide a simple, memorable, and motivating message.

In the latest version, the Pyramid shape was replaced with a much simpler plate graphic with a few key messages. Research is needed to determine whether this graphic, which still maintains several food categories, should be simplified further. In addition, a number of other countries continue to use complicated dietary guideline graphics that would likely benefit from being made simpler, including pyramid shapes (Spain, India, Greece, Switzerland, and Germany), a rainbow (Canada), a train (Colombia), or a loop (Argentina).

\section{Menu Labeling: Status Quo Bias, Compensation, and Simplicity}

Menu labeling is a national policy that requires chain restaurants to display calorie information at the point of purchase on their menus and menu boards. One rationale for this policy is to counter the status quo bias by making caloric information effortlessly accessible. Although some patrons might be interested in knowing the nutritional content of restaurant food, less than $0.1 \%$ of fast-food customers seek out nutrition information when it is available in restaurants but effortful to access. ${ }^{47}$ People are also notoriously bad at estimating the calories in restaurant food. ${ }^{48}$

Research on the effectiveness of menu labeling is mixed; some studies ${ }^{49-54}$ found it promotes lowercalorie purchases or consumption, whereas others ${ }^{55-59}$ have found minimal effects. Several behavioral science insights offer suggestions for ways to improve menu labeling. For example, in a randomized, controlled, laboratory study, Roberto et al. ${ }^{54}$ found that adults viewing calorie labels on menus during a dinner meal ordered and ate less at the meal. However, those who viewed menus with calorie labels later compensated for this difference by eating more when they went home after dinner, such that there was no calorie deficit for this group when compared to the control group that had no labels on their menus. However, another study group who received a menu with calorie labels and a label indicating that an average adult should consume 2,000 calories daily consumed fewer calories at dinner but did not eat more after the dinner; on average, that group consumed 250 calories less than the other two groups. This suggests that calorie labels may be more effective when the recommended daily caloric intake is made salient. Proposed U.S. Food and Drug Administration menu labeling regulations include daily caloric information to put calories in context. However, children who have lower caloric needs and consumers pursuing weight loss might benefit from being anchored to a lower number.

Although some research has found that menu labeling modestly affects behavior, it still relies on providing consumers with numeric data that lacks clear evaluative labels. Examples of more effective ways to present this information might include ranking menu items from low to high caloric content, using traffic lights to highlight low- and high-calorie items, ${ }^{28,60}$ or translating calorie information into easy-to-understand metrics, such as the amount someone would need to walk to burn off those calories. $^{61}$

\section{Restaurant Portion Sizes: Status Quo Bias, Compensation, and Substitution}

Large portion sizes are a common, influential default at restaurants. Research shows that people eat more food when served larger portions ${ }^{62,63}$ and although many people report preferring smaller portion sizes at restaurants, virtually no one spontaneously asks to be served a smaller portion when dining out. ${ }^{64}$ However, when people at a fast-food chain were asked whether they wanted to downsize their portion of a side dish to save calories, one third opted to do so and consumed fewer calories than those who did not accept the downsize nudge.

Although there is debate about whether New York City's proposal to place a 16-ounce limit on containers used to serve sugar-sweetened drinks in restaurants is a true "nudge," it was arguably designed with behavioral science in mind. ${ }^{65}$ Research has found that sugarsweetened beverages contribute to weight gain and poor health $^{66-69}$ and that some people want smaller portions. There is also little to no incentive for restaurants to voluntarily offer smaller portions. By leveraging the status quo bias, the policy would likely reduce calories 
consumed from sugar-sweetened beverages because people are unlikely to overcompensate by buying multiple drinks unless they are highly motivated to do so. This policy is consistent with Camerer and colleagues ${ }^{370}$ concept of asymmetric paternalism because it creates large benefits for individuals who are boundedly rational, while imposing little or no harm for those who are fully rational (e.g., those who are really thirsty can still purchase two 16-ounce drinks). However, it is important to evaluate whether people compensate by buying multiple drinks or consuming more sugar-sweetened beverages later in the day or make substitutions, such as buying more alcohol instead of sugar-sweetened beverages.

\section{Conclusions}

The behavioral sciences can shed light on important factors contributing to the cause and maintenance of public health problems like obesity. This knowledge should inform the design of public health interventions. This paper focuses on a handful of behavioral science insights that help explain why it is difficult to eat healthfully in the current food environment, but there are certainly others at play. We argue that nutrition interventions can be improved by altering default options, disseminating simple and meaningful nutrition information, carefully constructing the framing of public health messages, and working to minimize unintended consequences of interventions by considering decision-making processes. Although this paper focuses on obesity and food policy, the discussed insights are relevant to many other public health challenges like tobacco and alcohol consumption.

No financial disclosures were reported by the authors of this paper.

\section{References}

1. Thaler RH, Sunstein CR. Nudge: improving decisions about health, wealth, and happiness. New York NY: Penguin Group, 2008.

2. Thorgeirsson T, Kawachi I. Behavioral economics: merging psychology and economics for lifestyle interventions. Am J Prev Med 2013;44(2): 185-9.

3. WHO. Obesity and overweight: fact sheet no. 311. Reviewed: May 2014. www.who.int/mediacentre/factsheets/fs311/en/.

4. Roberto CA, Brownell KD. The imperative of changing public policy to address obesity. In: The Oxford handbook of the social science of obesity. Oxford UK: Oxford University Press, 2011.

5. Gearhardt AN, Bragg MA, Pearl RL, Schvey NA, Roberto CA, Brownell KD. Obesity and public policy. Annu Rev Clin Psychol 2012;8:405-30.

6. Glickman D, Parker L, Sim LJ, Del Valle Cook H, Miller EA, eds. Accelerating progress in obesity prevention: solving the weight of the nation. Washington DC: The National Academies Press, 2012.
7. Muraven M, Baumeister RF. Self-regulation and depletion of limited resources: does self-control resemble a muscle? Psychol Bull 2000;126 (2):247-59.

8. Simon H. Bounded rationality in social science: today and tomorrow. Mind Society 2000;1:25-39.

9. Ainslie G. Specious reward: a behavioral theory of impulsiveness and impulse control. Psychol Bull 1975;82(4):463-96.

10. Frederick SL, Loewenstein G, O’Donoghue T. Time discounting and time preference: a critical review. J Econ Lit 2002;40(2):351-401.

11. O'Donoghue T, Rabin M. The economics of immediate gratification. J Behav Decis Mak 2000;13(2):233-50.

12. Buehler RG, Griffin D, Ross M. Exploring the "planning fallacy:" why people underestimate their task completion times. J Pers Soc Psychol 1994;67(3):366-81.

13. Wansink B. Mindless eating: why we eat more than we think. New York NY: Bantam Dell, 2010.

14. Samuelson W, Zeckhauser R. Status quo bias in decision making. J Risk Uncertain 1998;1:7-59.

15. Tversky A, Kahneman D. Judgment under uncertainty: heuristics and biases. Science 1974;185(4157):1124-31.

16. Wansink B. Can package size accelerate usage volume? J Mark 1996;60 (3):1-14.

17. Kahneman D. Thinking fast and slow. New York NY: Farrar, Straus and Giroux, 2011.

18. Dehaene S. The number sense: how the mind creates mathematics. New York NY: Oxford University Press, 1997.

19. Paulos JA. Innumeracy: mathematical illiteracy and its consequences. New York NY: Hill and Wang, 1988.

20. Peters E, Vastfjall D, Slovic P, Mertz CK, Mazzocco K, Dickert S Numeracy and decision making. Psychol Sci 2006;17(5):407-13.

21. Peters E, Dieckmann N, Dixon A, Hibbard JH, Mertz CK. Less is more in presenting quality information to consumers. Med Care Res Rev 2007;64(2):169-90.

22. Fagerlin A, Wang C, Ubel PA. Reducing the influence of anecdotal reasoning on people's health care decisions: is a picture worth a thousand statistics? Med Decis Making 2005;25(4):398-405.

23. Zikmund-Fisher BJ, Fagerlin A, Keeton K, Ubel PA. Does labeling prenatal screening test results as negative or positive affect a woman's responses? Am J Obstet Gynecol 2007;197(5):528 (e1-e6).

24. Food Marketing Institute. Facts Up Front GMA-FMI voluntary frontof-pack nutrition labeling system. 2012. www.fmi.org/docs/healthand-wellness/nk_style_guide_for_implementers-2012.pdf?sfvrsn $=2$.

25. Liu PJ, Wisdom J, Roberto CA, Liu LJ, Ubel PA. Using behavioral economics to design more effective food policies to address obesity. Appl Econ Perspect Pol 2013;36:6-24.

26. Malam S, Clegg S, Kirwan S, McGinigal S. Comprehension and use of UK nutrition signpost labelling schemes. Food Standards Agency 2009. www.food.gov.uk/multimedia/pdfs/pmpreport.pdf.

27. Sendhil M, Shafir E. Decision making and policy in contexts of poverty. In: Shafir E, ed. The behavioral foundations of public policy. Princeton NJ: Princeton University Press, 2013.

28. Thorndike AN, Sonnenberg L, Riis J, Barraclough S, Levy DE. A 2 phase labeling and choice architecture intervention to improve healthy food and beverage choices. Am J Public Health 2012;102: 527-33.

29. Entman RM. Framing: towards clarification of a fractured paradigm. J Commun 1993;43(4):51-8.

30. Dar-Nimrod I, Heine SJ. Genetic essentialism: on the deceptive determinism of DNA. Psychol Bull 2011;137(5):800-18.

31. McFerran B, Mukhopadhyay A. Lay theories of obesity predict actual body mass. Psychol Sci 2013;24(8):1428-36.

32. Chandon P, Wansink B. The biasing health halos of fast-food restaurant health claims: lower calorie estimates and higher side-dish consumption intentions. J Consum Res 2007;34(3):301-14. 
33. Roberto CA, Shivaram M, Martinez O, Boles C, Harris JL, Brownell KD. The Smart Choices front-of-package nutrition label. Influence on perceptions and intake of cereal. Appetite 2012;58(2):651-7.

34. Horgen KB, Brownell KD. Comparison of price change and health message interventions in promoting healthy food choices. Health Psychol 2002;21(5):505-12.

35. Scherer G. Smoking behaviour and compensation: a review of the literature. Psychopharmacology 1999;145(1):1-20.

36. Rosenkilde M, Auerbach P, Reichkendler MH, Ploug T, Stallknecht BM, Sjödin A. Body fat loss and compensatory mechanisms in response to different doses of aerobic exercise-a randomized controlled trial in overweight sedentary males. Am J Physiol Regul Integr Comp Physiol 2012;303(6):R571-R579.

37. Wansink B, Chandon P. Can "low-fat" nutrition labels lead to obesity? J Mark Res 2006;57:605-17.

38. Church TS, Martin CK, Thompson AM, Earnest CP, Mikus CR, Blair $\mathrm{SN}$. Changes in weight, waist circumference and compensatory responses with different doses of exercise among sedentary, overweight postmenopausal women. PLoS One 2009;4(2):e4515.

39. Rolls BJ, Roe LS, Kral TVE, Meengs JS, Wall DE. Increasing the portion size of a packaged snack increases energy intake in men and women. Appetite 2004;42(1):63-9.

40. Connolly GN, Alpert HR. Trends in the use of cigarettes and other tobacco products, 2000-2007. JAMA 2008;299(22):2629-30.

41. Marantz PR. Rethinking dietary guidelines. Crit Rev Food Sci Nutr 2010;50(S1):17-8.

42. Downs JS, Loewenstein G. Behavioral economics and obesity. In: Cawley J, ed. The Oxford handbook of the social science of obesity. Oxford UK: Oxford University Press, 2011.

43. Scott ML, Nowlis SM, Mandel N, Morales AC. The effects of reduced food size and package size on the consumption behaviors of restrained and unrestrained eaters. J Consum Res 2008;35(3):391-405.

44. Cochran W. The "what the hell" effect. Some effects of goal proximity and goal framing on performance. In: Martin LL, Tesser A, eds. Striving and feeling: interactions among goals, affect, and selfregulation. Mahwah NJ: Lawrence Erlbaum Associates, Inc, 1996.

45. Sunstein C. Simpler: the future of government. New York NY: Simon \& Schuster, 2013.

46. Riis J, Ratner R. Simplified nutrition guidelines to fight obesity. In: Batra R, Keller PA, Strecher VJ, eds. Leveraging consumer psychology for effective health communications: the obesity challenge. Armonk NY: ME Sharpe, 2011.

47. Roberto CA, Agnew H, Brownell KD. An observational study of consumers' accessing of nutrition information in chain restaurants. Am J Public Health 2009;99(5):820-1.

48. Block JP, Condon SK, Kleinman K, et al. Consumers' estimation of calorie content at fast food restaurants: cross sectional observational study. BMJ 2013;346:f2907.

49. Auchincloss AH, Mallya GG, Leonberg BL, Ricchezza A, Glanz K, Schwarz DF. Customer responses to mandatory menu labeling at fullservice restaurants. Am J Prev Med 2013;45(6):710-9.

50. Dumanovsky T, Huang CY, Nonas CA, Matte TD, Bassett MT, Silver LD. Changes in energy content of lunchtime purchases from fast food restaurants after introduction of calorie labelling: cross sectional customer surveys. BMJ 2011;343:d4464.

51. Bollinger B, Leslie P, Sorensen AT. Calorie posting in chain restaurants. Am Econ J. Econ Policy 2011;3(1):91-128.
52. Chu YH, Frongillo EA, Jones SJ, Kaye GL. Improving patrons' meal selections through the use of point-of-selection nutrition labels. Am J Public Health 2009;99(11):2001-5.

53. Krieger JW, Chan NL, Saelens BE, Ta ML, Solet D, Fleming DW. Menu labeling regulations and calories purchased at chain restaurants. Am J Prev Med 2013;44(6):595-604.

54. Roberto CA, Larsen PD, Agnew H, Baik J, Brownell KD. Evaluating the impact of menu labeling on food choices and intake. Am J Public Health 2010;100(2):312-8.

55. Finkelstein EA, Strombotne KL, Chan NL, Krieger J. Mandatory menu labeling in one fast-food chain in King County, Washington. Am J Prev Med 2011;40(2):122-7.

56. Wisdom J, Downs JS, Loewenstein G. Promoting healthy choices: information versus convenience. Am Econ J Appl Econ 2010;2(2):164-78.

57. Elbel B, Kersh R, Brescoll VL, Dixon LB. Calorie labeling and food choices: a first look at the effects on low-income people in New York City. Health Aff (Millwood) 2009;28(6):w1110-w1121.

58. Harnack LJ, French SA, Oakes JM, Story MT, Jeffery RW, Rydell SA. Effects of calorie labeling and value size pricing on fast food meal choices: results from an experimental trial. Int J Behav Nutr Phys Act 2008;5:63.

59. Tandon PS, Zhou C, Chan NL, et al. The impact of menu labeling on fastfood purchases for children and parents. Am J Prev Med 2011;41(4):434-8.

60. Liu PJ, Roberto CA, Liu LJ, Brownell KD. A test of different menu labeling presentations. Appetite 2012;59(3):770-7.

61. Bleich SN, Herring BJ, Flagg DD, Gary-Webb TL. Reduction in purchases of sugar-sweetened beverages among low-income black adolescents after exposure to caloric information. Am J Public Health 2012;102(2):329-35.

62. Diliberti N, Bordi PL, Conklin MT, Roe LS, Rolls BJ. Increased portion size leads to increased energy intake in a restaurant meal. Obes Res 2004;12(3):562-8.

63. Ello-Martin JA, Ledikwe JH, Rolls BJ. The influence of food portion size and energy density on energy intake: implications for weight management. Am J Clin Nutr 2005;82(1S):236S-241S.

64. Schwartz J, Riis J, Elbel B, Ariely D. Inviting consumers to downsize fast-food portions significantly reduces calorie consumption. Health Aff (Millwood) 2012;31(2):399-407.

65. New York City Department of Health and Mental Hygiene. From supersized to human-sized: reintroducing reasonable portions of sugary drinks in New York City. www.nyc.gov/html/doh/downloads/ pdf/boh/max_size_sugary_drinks_briefing.pdf.

66. Malik VS, Schulze MB, Hu FB. Intake of sugar-sweetened beverages and weight gain: a systematic review. Am J Clin Nutr 2006;84(2):274-88.

67. Pan A, Malik VS, Hao T, Willett WC, Mozaffarian D, Hu FB. Changes in water and beverage intake and long-term weight changes: results from three prospective cohort studies. Int J Obes (Lond) 2013;37(10): $1378-85$.

68. Ebbeling CB, Feldman HA, Chomitz VR, et al. A randomized trial of sugar-sweetened beverages and adolescent body weight. N Engl J Med 2012;367(15):1407-16.

69. Ebbeling CB, Feldman HA, Osganian SK, Chomitz VR, Ellenbogen SJ, Ludwig DS. Effects of decreasing sugar-sweetened beverage consumption on body weight in adolescents: a randomized, controlled pilot study. Pediatrics 2006;117(3):673-80.

70. Camerer C, Issacharoff S, Loewenstein G, O'Donoghue T, Rabin M. Regulation for conservatives: behavioral economics and the case for “asymmetric paternalism.”. Univ PA Law Rev 2003;151(3):1211-54. 